\title{
Thermal injury in pregnancy: predicting maternal and fetal outcome
}

\author{
P. Agarwal \\ Plastic surgery unit, Department of Surgery, N.S.C.B. Government Medical College, Jabalpur-482003, M. P., India.
}

Address for correspondence: Pawan Agarwal, 292/293, Napier Town, Jabalpur- 482001, M.P., India. E-mail: drpawanagarwal@yahoo.com

\section{ABSTRACT}

This study was undertaken to assess the parameters that may predict maternal and foetal outcome in 49 thermally injured pregnant women in a Plastic surgery unit in tertiary referral center in the last five years. There were 33 maternal deaths and 34 fetal deaths. In general, pregnancy as such does not influence maternal outcome after thermal injury. In first and second trimester best chance for foetal survival is to ensure maternal survival and in the last trimester fetal survival depends upon fetal maturity. Maternal survival is less likely if the burn wound exceeds $50 \%$ total body surface area. Thermal injury does increase the risk of spontaneous abortion and premature labour. Early obstetric intervention is indicated in patients with fatal burn and complications.

\section{KEY WORDS}

Pregnacy, Thermal injury, Outcome

\section{INTRODUCTION}

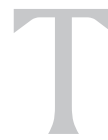

he literature on burns in pregnancy is limited but this condition is not uncommon in India. The incidence of female burn patients of reproductive age varies from $0.6 \%-15 \%$ in different series with highest incidence reported from India. ${ }^{1-7}$ Thermal injury sustained during pregnancy presents special management problems for the gravid woman and her foetus. The paucity of published data on the specific problems of burnt pregnant women has made it difficult to determine the incidence, morbidity, mortality rate or most effective management program for them. ${ }^{8}$ More information is required to provide guidelines for plastic surgeons and obstetricians, counseling the patients and her family for any additional risk of abortion, stillbirth, premature delivery, impaired foetal growth or malformations. In this study, an attempt was made to determine the factors responsible for poor maternal and foetal outcome in order to plan interventions to lower the morbidity and mortality. The present study describes the experience of 49 burn patients who were managed in a modest burn and plastic surgery setup with limited obstetric facilities.

\section{MATERIALS AND METHODS}

This is a retrospective study from 1998 to 2003 including 49 patients admitted in the burn and plastic surgery unit in tertiary referral center. In all patients the extent of burns was calculated by using the rule of 9's. A burn less than $10 \%$ in total body surface area (TBSA) was considered as a minor burn. A major burn was defined as a partial or full thickness burn affecting more than 10\% TBSA with 10-19\% being graded as moderately severe, $20-50 \%$ as severe and more than $50 \%$ as critical. All patients received routine thermal injury care, including fluid resuscitation, wound care and nutritional support. Patients were treated with $1 \%$ topical silver sulphadiazine and systemic antibiotics 
when indicated according to culture /sensitivity report. Wound care included hydrotherapy, desloughing, escharectomies, debridement and skin grafting. None of the patients underwent early excision and skin grafting. Nutritional support included daily intake of protein and calories according to the basal energy expenditure. Obstetric consultation was sought promptly on admission for each pregnant patient. Confirmation of pregnancy was done by history, physical examination, pregnancy test and ultrasonography of abdomen. State of foetus was recorded at admission and monitored. Maternal assessment included cause of burn, site, depth and extent of burn, burn related complications and maternal outcome. Foetal outcome was assessed in relation to gestational age, maternal TBSA involvement and complications.

\section{RESULTS}

49 patients age ranging from 18 years to 35 years (mean age 23.08 years) were assessed. All were in good health with normal pregnancies at the time of injury. The percentage of TBSA varied from $8 \%$ to $100 \%$ (mean $71.47 \%$ ). Four patients had minor and 45 patients had major burns. Resuscitation was successful in all patients except 13 who sustained $100 \%$ burn and died within 48 hours of admission to hospital. The injuries were predominantly domestic and fire and hot liquids were major causative factors. Gestational age at the time of injury varied from 8 weeks to 34 weeks with 11 cases in first trimester, 21 in second trimester and 17 patients in last trimester [Table 1]. Thirty three mothers died after sustaining severe burns and foetal deaths occurred in 34 of the 49 cases. With increasing TBSA burn complication rate and maternal and foetal loss increasesd. (Maternal mortality $21.42 \%$ in $<50 \%$ burn to $88.23 \%$ in $>50 \%$; Foetal mortality $28.57 \%$ in $<50 \%$ burn to $88.23 \%$ in $>50 \%$ )

Maternal outcome in relation to TBSA and maternal complications are shown in Table 2. Maternal death was directly attributable to irreversible burn shock in 15 cases, Septicemia in 8 cases and respiratory complications including smoke inhalation pulmonary edema and embolism in 10 cases. In TBSA $<50 \%$ only 3 out of 15 mothers died due to septicemia. In contrast when TBSA was $>50 \% 30$ out of 34 mothers died. Fetal death occurred in 34 of $49(69.3 \%)$ cases and was related to the extent of maternal burn. Fetal loss during first trimester was high (8 out of 11 mothers aborted). Twenty one mothers were seen in second trimester and 6 fetuses survived and the 17 fetuses 6 survived burn injury to mothers in the last trimester. Only one mother delivered a premature baby during initial hospital admission. The remaining pregnancies were continued normally but no information was available on the ultimate outcome of pregnancies carried to the term when patients were discharged before delivery.

\section{DISCUSSION}

The possibility of pregnancy must be considered when any woman of reproductive age sustains a burn injury. Although rare, an extensive burn during pregnancy is a serious complication. In this study, $12.29 \%$ of all women of reproductive age admitted with burns were pregnant. Because pregnancy tests were not done routinely the true incidence of pregnancy associated with burn injuries, especially in the first trimester, remains unknown. Therefore

Table 1: Relationship between gestational age and foetal outcome

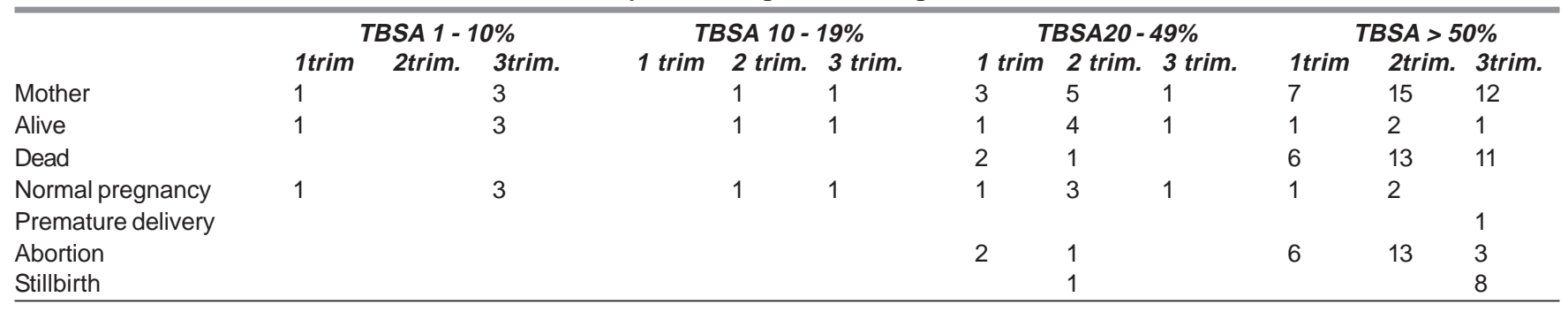

Table 2: Maternal burn size, complications and outcome

\begin{tabular}{|c|c|c|c|c|c|c|c|c|}
\hline \multirow[t]{2}{*}{ TBSA \% } & \multirow[t]{2}{*}{ Number } & \multirow[t]{2}{*}{ Irreversible burn shock } & \multirow[t]{2}{*}{ Respiratory complications } & \multirow[t]{2}{*}{ Septicemia } & \multicolumn{2}{|c|}{ Mother } & \multicolumn{2}{|c|}{ Foetus } \\
\hline & & & & & Alive & died & Alive & died \\
\hline$<10 \%$ & 4 & Nil & Nil & Nil & 4 & & 4 & \\
\hline $10-19 \%$ & 2 & Nil & Nil & Nil & 2 & & 2 & \\
\hline$>50 \%$ & 34 & 13 & 10 & 5 & 4 & 30 & 4 & 30 \\
\hline Total & 49 & 15 & 10 & 8 & 16 & 33 & 15 & 34 \\
\hline
\end{tabular}


all female burn patients of childbearing age should be tested for pregnancy unless the pregnancy is obvious. ${ }^{8}$ There are specific physiological changes that occur during pregnancy that may have an impact after thermal injury on maternal and foetal well-being. Burns cause many maternal physiological changes, and places additional stress on systems that are already highly modified. Pregnancy is associated with hyperdynamic cardiovascular state. After burns there is increased capillary permeability and third space loss leading to hypovolemia, which may in turn lead to hypotension if the patient is inadequately resuscitated. This may lead to placental insufficiency, fetal ischemia, hypoxia and acidosis, as the placenta is a less preferred site. All these events lead to premature labor. Thus aggressive fluid resuscitation, upright posture and oxygen supplementation should be provided to the mothers even in the absence of smoke inhalation. ${ }^{7,9}$

There is a linear co-relationship between the maternal total percentage of burns and the probability of death. ${ }^{6,10}$ In the present study, the fatality rate among patients with TBSA of $50 \%$ or more was 3.33 times the fatality rate among women with smaller burns. Percentage TBSA affected was therefore continues to be the best predictor of survival. Pregnancy as such does not pose any additional burden on the patients and their prognosis is same as non-burnt female. ${ }^{11,12}$

Fetal survival depends upon the gestational age, extent of maternal injury and maternal survival. In our study fetal survival during first trimester was $27.2 \%$ in comparison with $28.5 \%$ in second and $35.2 \%$ in third trimester. There was a significant correlation between fetal complications and the maternal percentage of TBSA burn. ${ }^{7}$ In this respect, fetal risk has been shown to increase with increasing maternal TBSA burns. Most fetuses survive when the mother survives and remain free of severe complications such as sepsis, hypotension and hypoxia. ${ }^{12,13}$ In the first trimester fetal loss is very high since 8 of the 11 mothers aborted. But out of these 11 mothers 7 were having burn $>50 \%$ TBSA. Therefore it is directly related with the extent of maternal thermal injury. In the second trimester fetal loss largely depended on maternal survival and majority of the fetuses survived if the mother survived the thermal injury. In the third trimester fetal survival is dependent more on gestational age and less on maternal survival. It is important to establish the gestational period precisely by the menstrual history and foetal ultrasound examination at the time of the burn accident that in turn determine the choice of obstetric procedures and ultimate foetal outcome. Fetuses delivered before 24 weeks generally will not survive, while those delivered after 32 weeks will do well with modem neonatal intensive care if born without hypoxia or birth trauma. Ex-utero survival of fetuses between 24 weeks to 32 weeks is difficult to predict therefore when preterm labour occurs, pharmacological inhibition of labour should be considered. Tocolytic therapy may be of value in preventing premature delivery or as a temporary method of arresting labour while maternal homeostasis is restored. ${ }^{14}$ The general scheme for the obstetric management of a pregnant burns patients is given in Table 3.

None of the patients in our series received tocolytic therapy and it should not be considered until the maternal injury has been stabilized and is contraindicated in patients with existing cardio-vascular or pulmonary disease. ${ }^{15}$ Parenteral magnesium sulfate is a better choice because it has less vasodilator and metabolic effects. ${ }^{16}$ Prevention of hypovolaemia and hypoxia is crucial since even a short

Table 3: The general scheme for the management of pregnancy in burns patients

\begin{tabular}{|c|c|c|c|}
\hline \multirow[t]{2}{*}{ Total \% burn } & \multicolumn{2}{|c|}{ Age of gestation } & Management \\
\hline & First trimester & & No obstetric interference \\
\hline \multirow{2}{*}{$<30$} & Third trimester & More than 36 wks & Induce labour / caesarian section \\
\hline & First trimester & & Foetal monitoring by ultrasound $3-4$ wks \\
\hline \multirow[t]{2}{*}{$30-50$} & Second trimester & & Foetal monitoring every 3-4 wks. Tocolytic therapy \\
\hline & Third trimester & More than 32 wks & Deliver foetus within $48 \mathrm{~h}$ \\
\hline \multirow[t]{4}{*}{$50-70$} & Second trimester & & Terminate pregnancy \\
\hline & Third trimester & If baby is viable & Induce labour / caesarian section within $24 \mathrm{~h}$ \\
\hline & & Intrauterine death & No active intervention up to $4 \mathrm{wks} /$ monitoring of foetus of haemocoagulation factors \\
\hline & First trimester & & No treatment \\
\hline \multirow[t]{2}{*}{$>70$} & Second trimester & & No treatment \\
\hline & Third trimester & & Caesarian section as an emergency procedure at the earliest \\
\hline
\end{tabular}


period of maternal hypoxia can lead to precipitation of labour or fetal death. An additional factor is invasive burn wound sepsis, which may result in premature labour and adverse vasoactive effects. Thermally injured tissue produces prostaglandins and increases the synthesis of free arachidonic acid. Organisms in the burn wound contribute to these effects. This increases uterine contractility thus initiating premature labour and abortion. ${ }^{4,17}$ Obstetric considerations affect the choice of route and the timing of the delivery; spontaneous vaginal delivery is generally preferred even in presence of perineal burns. When there are obstetric indications for a caesarian section, this can be performed safely even when the lower abdominal wall is burnt. In a stable patient with less than $50 \%$ burn if the foetus is immature, premature labour could be suppressed and pregnancy allowed to continue until term. If burn wound exceeds 50\% TBSA and foetus is at risk, obstetric intervention is indicated within the first 24 hours for highrisk third trimester pregnancies. ${ }^{18}$ Other indications for obstetric intervention include progressive foetal distress or significant maternal complications.

Principles of management of a preganant burns patient is not different from non pregnant burns patient. ${ }^{19}$ It includes early and adequate resuscitation, combating sepsis by limited choice of antibiotics and local antibacterial agents, early surgical intervention, adequate nutrition and close

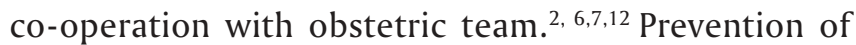
hypovolaemic shock by adequate early fluid therapy is required to maintain the uterine blood flow, which in turn maintains foetus tissue $\mathrm{pO}_{2}$ levels within the normal range. It is recommended to maintain the mother's blood pressure within the normal range and a urine output of 30-60 ml/h. In cases of inhalation injury, ventilatory support may be required. Ventilatory support should be initiated when maternal $\mathrm{pO}_{2}$ is less than $60 \mathrm{~mm} \mathrm{Hg}$ as inhaled carbon monoxide can cross the placental barrier to compete for binding sites on foetal hemoglobin, provoking foetal cardiac edema, and affecting cardiac development. Burns complicated by pregnancy considerably reduces use of the commonly used drugs like Chloramphenicol, Aminoglycoside Tetracycline Ciprophloxacin Vancomycin, Rifampicin, Sulpha drugs, Salicylates and Povidone iodine for systemic and topical treatment of burns. ${ }^{19}$ The only antibiotics that can be considered safe in pregnancy are the penicillin and cephalosporins, other commonly used antibiotics (Imipenem, teicoplanin) should be avoided during pregnancy unless they are necessary and their advantages outweigh any possible risk. Under anesthesia it is important to avoid the use of ketamine, which increases the excitability of the myometrium and may trigger effective uterine contractions; also, when the pregnancy is near term and delivery is imminent, ketamine may cause respiratory depression in the neonate. ${ }^{19}$ Similarly, depolarizing agents like succinylcholine should not be used as it causes hyperkalemia, instead a non-depolarizing muscle relaxant like curare or pancuronium is preferred. ${ }^{20}$ Povidone-iodine is widely used for bums cleansing but if used for $>20 \%$ of burns large amounts of iodine can be absorbed through the burn wound and pass through the placenta to affect thyroid functions and cause metabolic acidosis. Sulpha drugs (silver sulphadiazine) are also potentially teratogenic if administered before the 14th week of pregnancy and lead to growth retardation and low birth weight if subsequently administered. Certain other uncommon topical antibiotics like Chloramphenicol, either in powder form or as an ointment in association with collagenase, are teratogenic in first trimester and responsible for gray baby syndrome in the third trimester. Gentamicin is capable of passing through the placenta after absorption through burns wounds and can lead to ototoxicity and nephrotoxicity if used after the 14th week of pregnancy. Rifamycin for local use is absolutely contraindicated in the last period of pregnancy because its interference with bilirubin metabolism can cause indirect hyperbilirubinaemia, with the risk of kemicterus. Salicylates exert an antiprostaglandin action and may therefore have a protective effect on pregnancy. For the same reason they should not be used in the final period of pregnancy because they prolong gestation and delay spontaneous delivery.

Early coverage of the burns by tangential excision and splitthickness skin grafting facilitates healing of the wounds and minimizes septic complications thus improving maternal and foetal outcome. ${ }^{21,22}$ Wounds over the abdomen and breast should be treated first. Early healing of the abdominal wound favors pain-free stretching of the abdominal skin during the developing pregnancy, facilitates obstetric supervision of the growing foetus and performance of caesarian section if required. Early surgery and healing of the breast wound prevents infection and sloughing of nipples and permits subsequent breastfeeding. ${ }^{9,19}$

Pregnant women with self-inflicted burns have more fatality rate as compared to unintentional burns. This difference in mortality may be attributable to the higher percentage of TBSA burned in suicidal burn patients compared with 
women with accidental burns. Burns sustained by pregnant women occur in similar circumstances as non-pregnant women and most of them are in good health. Like all burn wound management, once the resuscitation is complete the goal is to combat sepsis, achieve early wound coverage and provide adequate nutrition during convalescence. Since the patient is recumbent for long period whenever possible left lateral position is recommended to prevent uterine compression of inferior vena cava.

Long-term follow-up of the patients with severe abdominal wall scarring showed that pregnancies could be accommodated normally without increasing the risk of abortion, premature labour or difficulty during labour.

Scarred abdomen does not pose any difficulty for caesarean section. ${ }^{23,24}$ The best chance for pregnant burned patients lies in prevention or decreasing the extent of burn by counseling, prohibiting the use of explosive kerosene stoves and proper primary aid to burn victims. Plastic surgeons and obstetricians should work in close association for management of this difficult problem. ${ }^{25}$ Emphasis should be on burn prevention.

\section{CONCLUSION}

In general, pregnancy as such does not influence maternal outcome after thermal injury and best chance for foetal survival is to ensure maternal survival. Maternal survival is less likely if the burn wound exceeds $50 \%$ total body surface area. Thermal injury does increase the risk of spontaneous abortion and premature labour and foetal survival depends upon foetal maturity.

\section{REFERENCES}

1. Mulla N, Albuquerqui MD, Mex N. Labour following severe thermal burns. Am J Obstet Gynecol 1958;76:1338-41.

2. Matthews RN. Obstetric implications of burns in pregnancy. $\mathrm{Br} \mathrm{J}$ Obstet Gynaecol 1982;89:603-9.

3. Schmitz JT. Pregnant patients with burns. Am J Obstet Gynecol 1971;110:57.

4. Stage HA. Severe burns in the pregnant patients. Obstet Gynecol 1973 42:259-62.

5. Stilwell JH. A major burn in early pregnancy with maternal survival and pregnancy progressing to term. Br J Plast Surg 1982;35:335.

6. Rayburn W, Smith B, Feller I, Varner M, Cruikshank D. Major burns during pregnancy:Effects on foetal well-being. Obstet Gynecol 1984;63:392-5.

7. Taylor JW, Plunkett GD, McManus WF, Pruitt BA. Thermal injury during pregnancy. Obstet Gynecol 1976;47:434-8.

8. Guo SS, Greenspoon JS, Kahn AM. Management of burn injuries during pregnancy. Burns 2001;27:394-7.

9. Bartle EJ, Sun JH, Wang XW. Burns in pregnancy. J. Burn Care Rehabil 1988;9:485-7.

10. Cheah SH, Sivanesaratnam V. Burns in pregnancy-maternal and foetal prognosis. Aust. N. Z. J. Obstet. Gynaecol 1989;29:143-5.

11. Akhtar MA., Mulawkar PM, Kulkarni HR. Burns in pregnancy:Effect on maternal and foetal outcomes. Burns 1994;20:351-5.

12. Amy BW, McManus WF, Goodwin CW, Mason A, Pruitt BA. Thermal injury in the pregnant patient. Surg Gynecol Obstet 1985;161:209-12.

13. Rode H, Millar AJ, Cywes S, Bloch CE, Boes EG, Theron EJ, Lodder JV, van der Merwe AE, de Kock M. Thermal injury in pregnancy-the neglected tragedy. S Afr Med J 1990;77:346-8.

14. Deitch EA, Rightmire DA, Clothier J, Blass N. Management of burns in pregnant women. Surg. Gynecol Obstet 1985;161:1-4.

15. Benedetti TJ. Maternal complications of parenteral beta sympathomimetic therapy for premature labor. Am J Obstet Gynaecol 1983;145:1-6.

16. Barden TP. Premature labour. In: RT Bolognese, RH Schwarz, Schneider J, editors. Perinatal medicine, Management of highrisk fetus and neonate. $2^{\text {nd }}$ edn. Baltimore:Williams and Wilkins, co; 1982. p. 240-303.

17. Herndon DN, Abston S, Stein MD, Increased thromboxane $B_{2}$ levels in the plasma of burned and septic burned patients.Surg Gynaecol Obstet 1984:159:210-3.

18. Ullmann Y, Blumenfeld Z, Hakim M, Mahoul I, Sujov P, Peled IJ. Urgent delivery, the treatment of choice in term pregnant women with extended burn injury. Burns 1997;23:157-9.

19. Napoli B, D'Arpa N, Masellis M, Graziano R. Burns in pregnancy Annals of Burns and Fire Disasters - vol XIII-n 1 - March 2000

20. Gronert GA, Theye RA. Pathophysiology of hyperkalemia induced by succinylcholine. Anesthesiology 1975;43:89-99.

21. Mabrouk AR, El-Feky AEH. Burns during pregnancy: A gloomy outcome. Burns 1997;23:596-60.

22. Prasanna M, Singh K. Early burn wound excision in 'major' burns with 'pregnancy':a preliminary report. Burns 1996;3:234-37.

23. Kitzmiller WJ, Neale HW, Warden GD, Smith D. The effect of full-thickness abdominal wall burns sustained during childhood on subsequent childbearing ability. Ann Plast Surg 1998;40:1113.

24. McCauley RL, Stenberg BA, Phillips LG, Blackwell SJ, Robson MC. Long-term assessment of the effects of circumferential truncal burns in pediatric patients on subsequent pregnancies. J Burn Care Rehabil 1991;12:51-3.

25. El-Gallal ARS., Yousef SM. burns in pregnancy:a ten-year review of admitted patients Annals of Burns and Fire Disasters-vol. XV-n. 3 September 2002. 